\title{
The character of dual site adsorbent on coal fly ash toward $\mathrm{Pb}$ (II) adsorption
}

\author{
Widi Astuti ${ }^{1}$, Endang Tri Wahyuni ${ }^{2}$, Agus Prasetya $^{3}$, I Made Bendiyasa ${ }^{3}$ \\ ${ }^{I}$ Chemical Engineering Department, Semarang State University, Semarang 50229, Indonesia \\ ${ }^{2}$ Chemistry Department, Gadjah Mada University, Yogyakarta 55281, Indonesia \\ ${ }^{3}$ Chemical Engineering Department, Gadjah Mada University, Yogyakarta 55281, Indonesia
}

\begin{abstract}
Coal fly ash (CFA), generated during combustion of coal in the electricity production is recognized as an environmental pollutant. CFA is composed primarily of some oxides including $\mathrm{SiO}_{2}, \mathrm{Al}_{2} \mathrm{O}_{3}$ having active site and unburned carbon that anables it to act as a dual site adsorbent. However, the existence of unburned carbon in coal fly ash can generate two possibilities. It can improve the adsorption capacity, or contradictionly hinder the adsorption. The aim of this paper is to study the contribution of unburned carbon on coal fly ash toward characters, adsorption capacity and adsorption mechanism. In this context, CFA with various unburned carbon content were employed as adsorbent of $\mathrm{Pb}$ (II) in aqueous solutions. The research shows that the existence of unburned carbon in CFA leads to the increase of specific surface area and pore size, but the adsorption capacity for $\mathrm{Pb}$ (II) decrease. Adsorption kinetics of $\mathrm{Pb}(\mathrm{II})$ onto CFA could be approximated with a pseudo second order kinetic model with the rate constant was $0.298 \mathrm{~g} \cdot \mathrm{mg}^{-1} \cdot \mathrm{min}^{-1}$.
\end{abstract}

Keywords: - coa fly ash, unburned carbon, dual site adsorben, $P b(I I)$, adsorption

\section{INTRODUCTION}

Coal fly ash, generated during the combustion of coal in power plant, is an industrial by-product which is recognized as an environmental pollutant. Increasing concern about the environmental consequences of such disposal have led to investigations into other possible utilization avenues, including as adsorbent. However, the adsorption capacity of CFA is not very high. Several authors have reported the conversion of coal fly ash into zeolite and used it to reduce heavy metal and dye concentrations from aqueous solutions $[1,5,6,7,8]$. Zeolite is regarded as an effective but expensive adsorbent due to its high cost of manufacturing. In order to improve the efficiency of adsorption processes, it is necessary to develop cheaper adsorbents with high adsorption capacities.

CFA contains mineral composed of $\mathrm{SiO}_{2}, \mathrm{Al}_{2} \mathrm{O}_{3}$ having active site and unburned carbon that anables it to act as a dual site adsorbent. However, the existence of unburned carbon in coal fly ash can generate two possibilities. It can improve the adsorption capacity, or contradictionly hinder the adsorption. It has not been explored yet. The aim of this paper is to give a contribution for understanding the effect of unburned carbon on coal fly ash toward characters, adsorption capacity and adsorption mechanism. In this context, $\mathrm{Pb}(\mathrm{II})$ is choosen because it is one of the major pollutants which is primarily discharged from printing, paper, ammunition and electroplating industries to the water and environment.

\subsection{Sampel Preparation and Characterization}

\section{MATERIALS AND METHODS}

The effect of unburned carbon on coal fly ash toward characters, adsorption capacity and adsorption mechanism was evaluated by reducing and increasing unburned carbon content to obtained CFA having various unburned carbon content. CFA was collected from electrostatic precipitators of Tanjungjati power plant, Jepara, Indonesia. Before any treatment, it was washed with deionized water and dried. CFA was further treated with various sulfuric acid concentration $(50$ to $75 \mathrm{w} / \mathrm{w})$, temperatures $\left(60\right.$ to $\left.90^{\circ} \mathrm{C}\right)$ for three to six hours to reduce unburned carbon content. The ratio of CFA weight to sulfuric acid volume was $1 \mathrm{~g}$ of CFA to $6 \mathrm{~mL}$ of sulfuric acid. For each run, one variable was varied and two others were fixed. Finally the CFA was filtered, washed several times with deionized water until $\mathrm{pH}$ of the filtrate was around 7 , dried at $110^{\circ} \mathrm{C}$, characterized and then used as an adsorbent in the sorption experiments. The unburned carbon content on CFA was also reduced by heating at $400-800^{\circ} \mathrm{C}$ for 1 hour. In addition, the effect of unburned content were also evaluated by reducing mineral content on CFA through a BSS Tyler Sieve of 100-mesh size. CFA that do not pass 100 mesh sieve was used, because it had quite high unburned carbon content.

The chemical composition of original CFA was analyzed using x-ray fluorescence (XRF). X-ray diffraction (XRD) patterns for original and treated CFA were obtained by powder method using $\mathrm{Cu}$ Ka radiation (Schimadzu XRD-6000). The Brunauer-Emmett-Teller (BET) surface area and pore size were characterized by 
$\mathrm{N}_{2}$ physisorption at $77 \mathrm{~K}$ using NOVA 1200 microanalyzer. While, the morphology of CFA surface was obtained from scanning electron microscope (SEM).

\subsection{Batch Adsorption Experiment}

Original or treated CFA $(1 \mathrm{~g})$ was put into an erlenmeyer filled $50 \mathrm{~mL}$ of $\mathrm{Pb}$ (II) solution. $\mathrm{Pb}$ (II) solution concentrations were varied from 10 to $1000 \mathrm{mg} \cdot \mathrm{dm}^{-3}$. The adsorption was carried out at $\mathrm{pH}$ of 5 . The erlenmeyer contained the mixture was placed in a waterbath at $26^{\circ} \mathrm{C}$ and shaken mechanically for 5 to 180 minutes. Subsequently, suspended solid was filtered and the filtrate was analyzed to determine $\mathrm{Pb}$ (II) concentration using atomic absorption spectrophotometer. To investigate the effect of $\mathrm{pH}$ on adsorption, $1 \mathrm{~g}$ of original or treated CFA was added to an erlenmeyer filled $50 \mathrm{~mL}$ of $10 \mathrm{ppm} \mathrm{Pb}$ (II) solution. The $\mathrm{pH}$ was adjusted with base/acid to an appropriate $\mathrm{pH}$ (pH range of 3 to 9 ). The erlenmeyer filled the mixture was placed in a waterbath at $26^{\circ} \mathrm{C}$ and shaken mechanically for 180 minutes. The ash was separated from the solution and the filtrate was analyzed to determine $\mathrm{Pb}$ (II) concentration using atomic absorption spectrophotometer.

\section{RESULTS AND DISCUSSION}

\subsection{Characterization of CFA}

The original CFA employed in this research shows the presence of significant fractions of $\mathrm{SiO}_{2}$ and $\mathrm{Al}_{2} \mathrm{O}_{3}$, as reported in Table 1. The silico-aluminous nature of the ashes is confirmed by XRD. Fig. 1 clearly shows the peaks of quartz and mullite which are crystalline phases of $\mathrm{SiO}_{2}$ and $3 \mathrm{Al}_{2} \mathrm{O}_{3} .2 \mathrm{SiO}_{2}$, respectively. Difractogram of treated CFA is reflected in Fig. 2. It shows several sharp diffraction peaks that were different with diffractogram of original CFA. At heating treatment, the intensity of quartz decreases. While, at $\mathrm{H}_{2} \mathrm{SO}_{4}$ treatment, hydroxysodalite $\left(\mathrm{Na}_{6}\left(\mathrm{Si}_{6} \mathrm{Al}_{6} \mathrm{O}_{24}\right) .8 \mathrm{H}_{2} \mathrm{O}\right)$ can be identified. Similar observations were made by Woolard [2] who found hydroxysodalite at $\mathrm{NaOH}$ treated CFA.

\begin{tabular}{|c|c|}
\hline Component & Content (mass \%) \\
\hline $\mathrm{SiO}_{2}$ & 36.47 \\
\hline $\mathrm{Al}_{2} \mathrm{O}_{3}$ & 19.27 \\
\hline $\mathrm{CaO}$ & 6.56 \\
\hline $\mathrm{MgO}$ & 2.94 \\
\hline $\mathrm{Fe}_{2} \mathrm{O}_{3}$ & 10.74 \\
\hline $\mathrm{MnO}$ & 0.07 \\
\hline $\mathrm{Na}_{2} \mathrm{O}$ & 1.76 \\
\hline $\mathrm{K}_{2} \mathrm{O}$ & 1.77 \\
\hline $\mathrm{CuO}$ & 0.01 \\
\hline $\mathrm{As}_{2} \mathrm{O}_{3}$ & 0.01 \\
\hline $\mathrm{P}_{2} \mathrm{O}_{5}$ & 0.25 \\
\hline $\mathrm{SO}_{3}$ & 1.04 \\
\hline unburned carbon & 19.11 \\
\hline
\end{tabular}

Fig. 3 illustrated SEM micrograph of the original CFA. Most of CFA mineral have smooth surface, whereas others have rougher surface because the surface is covered by unburned carbon, as can be seen in Fig. 3 b. Besides covers CFA mineral surface, unburned carbon is also randomly distributed as a mesopore material. Specific surface area (SSA) and pore diameter of CFA are presented in Fig. 4 and Table 2, respectively. The existence of unburned carbon in CFA leads to the increase of SSA and pore diameter. It is because unburned carbon is a porous material that contributes to the increase of SSA and pore size. Montagnaro and Santoro [3] also noted an increase in the SSA of CFA as a result of the existence of unburned carbon in CFA.

Table 2. Pore Size of CFA

\begin{tabular}{lcc}
\hline & unburned carbon content $(\%)$ \\
& 19,11 & 46,15 \\
\hline pore size $(\mathrm{nm})$ & 3,055 & 3,384 \\
\hline
\end{tabular}

\subsection{Effect of sulfuric acid, heating and sieving treatment toward unburned carbon content}

Fig. 5 demonstrates that sulfuric acid treatment causes a decrease of unburned carbon content in CFA. At constant sulfuric acid concentration and processing time, higher temperature causes unburned carbon content in CFA decrease. At constant temperature and processing time, higher sulfuric acid concentration causes unburned carbon content in CFA decrease. While, at constant temperature and sulfuric acid concentration, longer processing time also causes unburned carbon content in CFA decrease. Heating from $400^{\circ} \mathrm{C}$ to $800^{\circ} \mathrm{C}$ 
causes a decrease of unburned carbon content. Higher temperature gives lower unburned carbon content. The decreasing of unburned carbon content caused by heating is more than that of caused by sulfuric acid treatment. Otherwise, sieving treatment leads to an increase of unburned carbon content in CFA.

\subsection{Pb (II) adsorption by CFA-unburned carbon as dual site adsorbent}

Fig. 6 shows that an increase of unburned carbon content on CFA causes adsorption capacity decrease. Even though unburned carbon can give a contribution to the $\mathrm{Pb}$ (II) adsorption, but the contribution of active sites on CFA mineral is higher than that of unburned carbon pore. A great amount of unburned carbon can form agregates and cover the active site on CFA surface, so chemical binding between the active sites and $\mathrm{Pb}$ (II) can not happen. Consequently, $\mathrm{Pb}(\mathrm{II})$ adsorption decrease. Desorption test using aquadest also shows that most of adsorption occur at the active site, as can be seen in Table 3. If $\mathrm{Pb}$ (II) can be desorbed by aquadest, it indicates that $\mathrm{Pb}$ (II) adsorption occurs at unburned carbon with weak interaction (physisorption). Otherwise, If $\mathrm{Pb}$ (II) $\mathrm{can}$ not be desorbed by aquadest, it indicates that $\mathrm{Pb}(\mathrm{II})$ adsorption occurs at active site with stronger interaction (chemisorption). Table 3 shows that only $4.53 \%$ of $\mathrm{Pb}$ (II) can be desorbed by aquadest. It indicates that most of adsorption occur at active site. The increase of unburned carbon content on CFA gives an increase of $\mathrm{Pb}(\mathrm{II})$ desorbed.

Table 3. Comparation of $\mathrm{Pb}(\mathrm{II})$ adsorbed and $\mathrm{Pb}(\mathrm{II})$ desorbed from CFA having various unburned carbon content

\begin{tabular}{lll}
\hline & \multicolumn{2}{c}{ unburned carbon content $(\%)$} \\
& 0,42 & 19,1 \\
\hline $\mathrm{Pb}$ (II) adsorbed, $\mathrm{mmol} / \mathrm{g}$ & 0,0599 & 0,0309 \\
$\mathrm{~Pb}$ (II) desorbed, $\mathrm{mmol} / \mathrm{g}$ & 0,0016 & 0,0014 \\
$\mathrm{~Pb}$ (II) desorbed, \% & 2,63 & 4,53 \\
\hline
\end{tabular}

Fig. 7 illustrates the adsorption behavior of various CFA as a function of $\mathrm{pH}$. It is apparent that in all cases, the amount of $\mathrm{Pb}(\mathrm{II})$ adsorbed increases as $\mathrm{pH}$ increases until $\mathrm{pH}=5$. However, at $\mathrm{pH}$ higher than 5, the amount of $\mathrm{Pb}(\mathrm{II})$ adsorbed decreases as $\mathrm{pH}$ increases. It is because, at high $\mathrm{H}^{+}$concentration, competition between $\mathrm{H}^{+}$ion and $\mathrm{Pb}(\mathrm{II})$ ion occurs so the adsorpstion capacity decreases. While, at lower $\mathrm{H}^{+}$concentrations, the active site becomes more negatively charge, so interaction between $\mathrm{Pb}$ (II) ion with active site occurs easily and the adsorption capacity increases. At $\mathrm{pH}$ higher than 6, metal precipitation occurs so $\mathrm{Pb}$ (II) adsorption decreases.

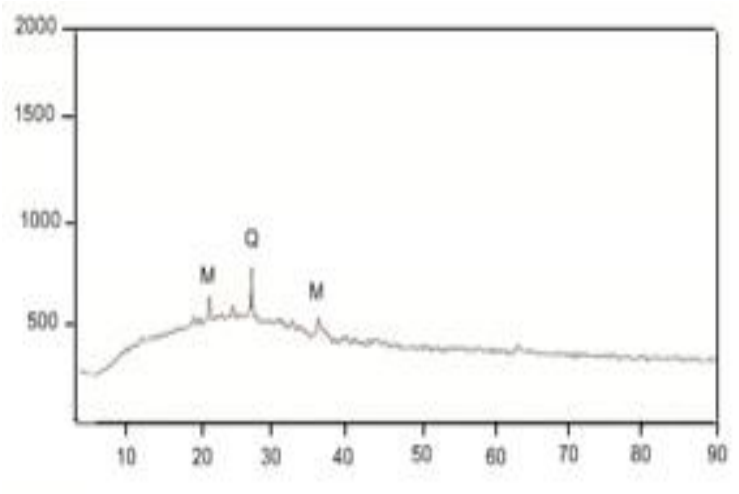

Fig. 1 : XRD patterns of original CFA

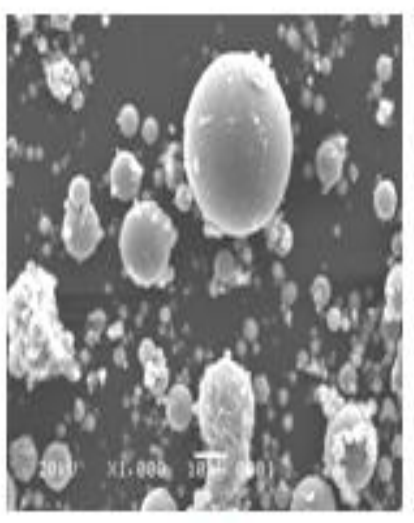

(a)

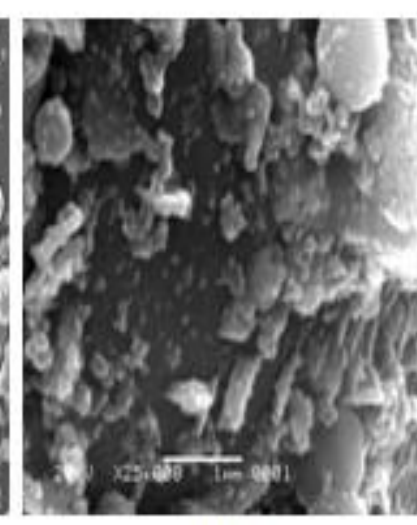

(b)
Fig. 3: SEM micrograph of CFA magnification: (a) $1000 \mathrm{x}$ (b) $25.000 \mathrm{x}$ 


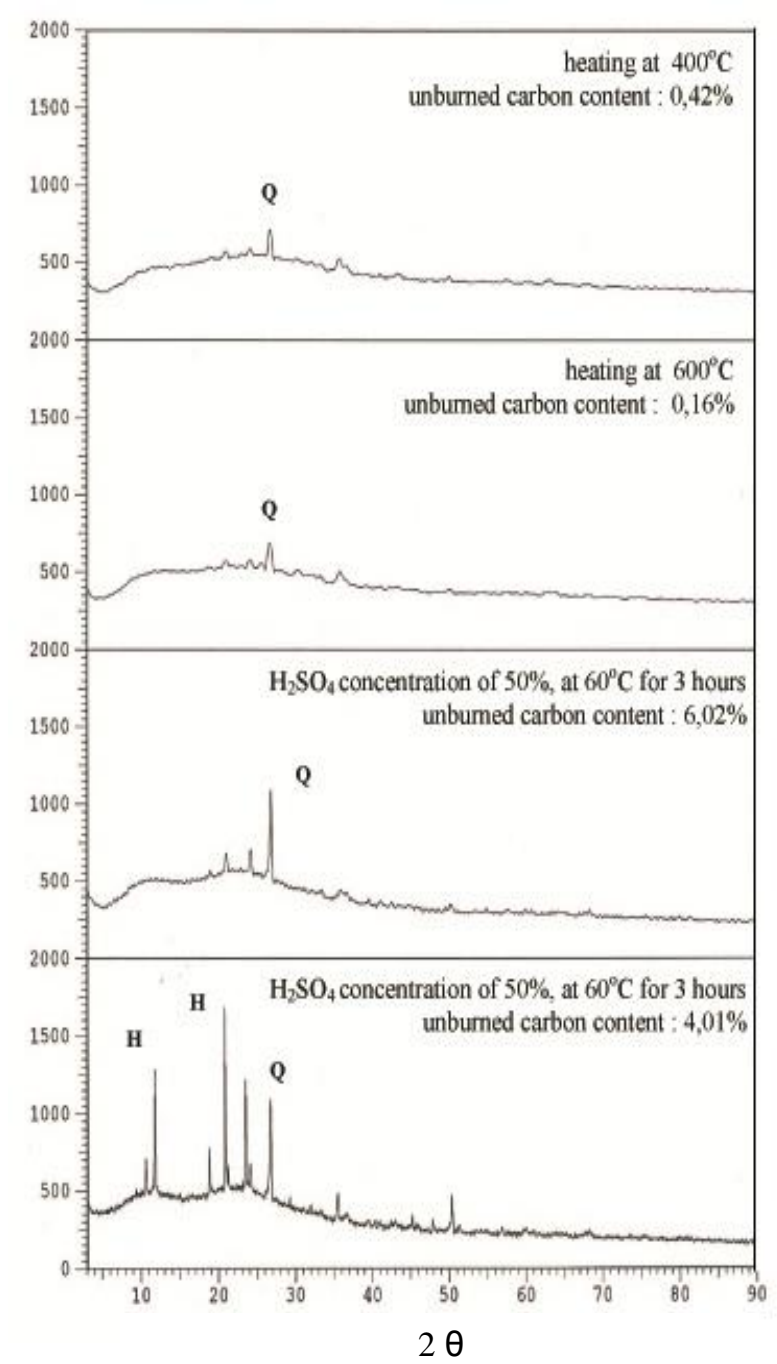

Fig. $2:$ XRD patterns of treated CFA

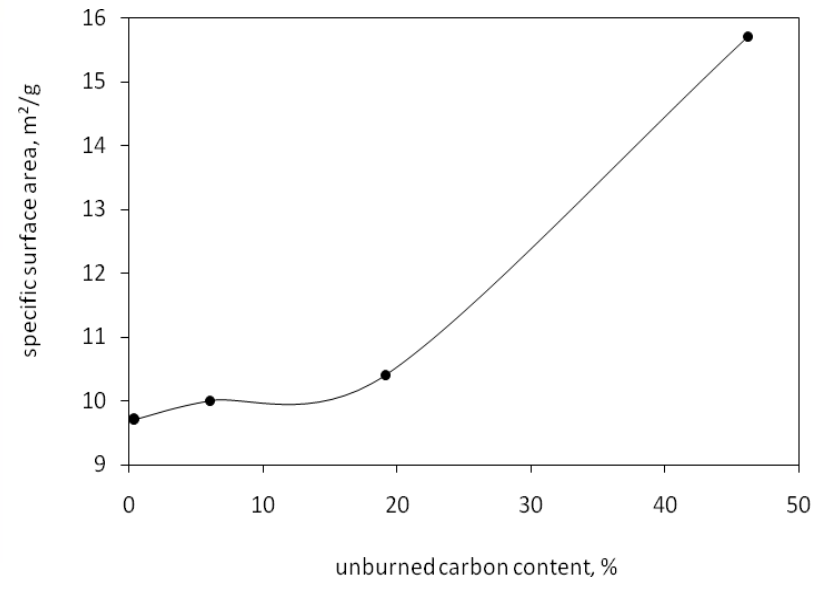

Fig. 4 : Specific surface area of treated CFA having various unburned carbon content

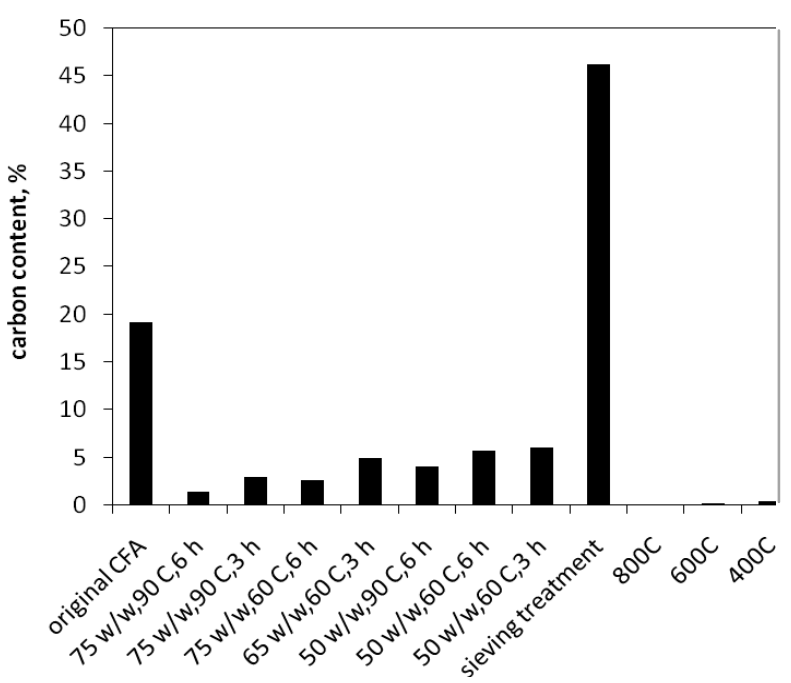

Fig. 5 : Carbon content of original and treated CFA Note : $\mathrm{x}$ w/w, y $\mathrm{C}, \mathrm{z}$ h means sulfuric acid concentration $(\mathrm{w} / \mathrm{w})$, temperature $\left({ }^{\circ} \mathrm{C}\right)$ and reflux time (hours)

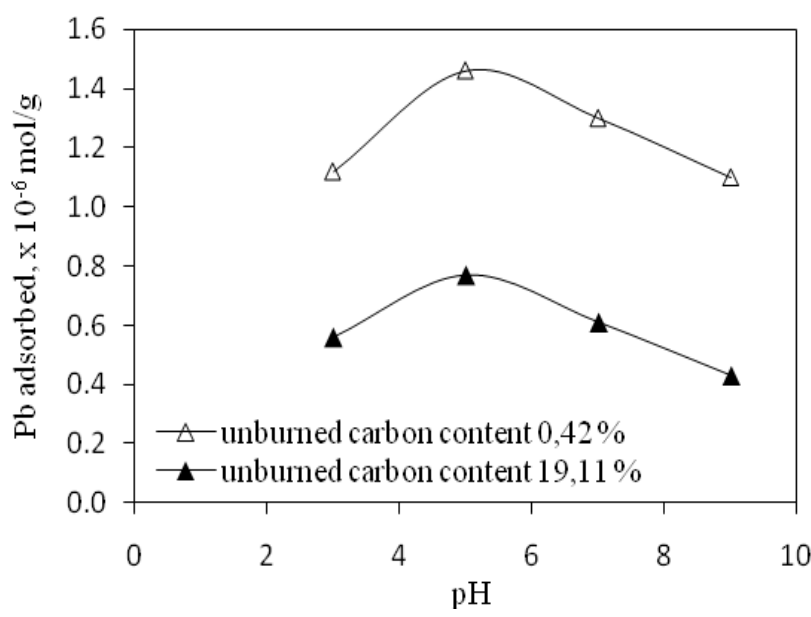

Fig. 7. Effect $\mathrm{pH}$ toward $\mathrm{Pb}(\mathrm{II})$ adsorbed

Fig. 6 : adsorption isotherm of $\mathrm{Pb}(\mathrm{II})$ in aqueous solution by CFA 


\subsection{Adsorption kinetics}

In order to clarify the adsorption kinetics of $\mathrm{Pb}$ (II) onto CFA, Lagergren's pseudo-first order and pseudo second order kinetic models were applied to the experimental data. The linearized form of the pseudo first order rate equation by Lagergren is given as [4] :

$$
\ln \left(q_{e}-q_{t}\right)=\ln q_{e}-k_{1} t
$$

where $\mathrm{q}_{\mathrm{e}}$ and $\mathrm{q}_{\mathrm{t}}$ are amounts of $\mathrm{Pb}(\mathrm{II})$ adsorbed on CFA surface at equilibrium (mg. $\mathrm{g}^{-1}$ ) and at time $\mathrm{t}\left(\mathrm{mg} \cdot \mathrm{g}^{-1}\right.$ ), respectively, $\mathrm{k}_{1}$ is the rate constant of pseudo first order model $\left(\mathrm{min}^{-1}\right)$ and $\mathrm{t}$ is time (min). The adsorption rate constants $\left(\mathrm{k}_{1}\right)$ can be determined experimentally by plotting of $\ln \left(\mathrm{q}_{\mathrm{e}}-\mathrm{q}_{\mathrm{t}}\right)$ versus t. Experimental data were also fitted for the pseudo second order [4] :

$$
\frac{t}{q_{t}}=\frac{1}{k_{2} q_{e}^{2}}+\frac{1}{q_{e}} t
$$

where $\mathrm{k}_{2}\left(\mathrm{~g} \cdot \mathrm{mg}^{-1} \cdot \mathrm{min}^{-1}\right)$ is the rate constant of the second order model. The adsorption rate constants $\left(\mathrm{k}_{2}\right)$ can be determined experimentally by plotting between $t / q_{t}$ versus $t$ where $q_{e}$ can be calculated from the slope of the straight line and $\mathrm{k}_{2}$ from its intercept. Tabel 4 illustrates the $\mathrm{k}_{1}$ and $\mathrm{k}_{2}$ for first and second order rate constants as well as $\mathrm{q}_{\mathrm{e}}$ for both of them. It shows that the experimental data fit with the second order model.

Table 4. Parameters for adsorption of $\mathrm{Pb}$ (II) onto CFA derived from the pseudo first and second order kinetic models

\begin{tabular}{llllll}
\hline $\begin{array}{l}\text { Pseudo first order } \\
\mathrm{q}_{\mathrm{e}}\left(\mathrm{mg} \cdot \mathrm{g}^{-1}\right)\end{array}$ & $\mathrm{k}_{1}(\mathrm{~min})$ & $\mathrm{R}^{2}$ & \multicolumn{2}{l}{ Pseudo second order } \\
\hline 0.293 & 0.029 & 0.949 & 0.481 & 0.298 & 0.997 \\
\hline
\end{tabular}

\section{CONCLUSION}

It is concluded that unburned carbon hinder $\mathrm{Pb}(\mathrm{II})$ adsorption. The increase of unburned carbon content on CFA leads to a decrease of adsorption capacity. The amount of $\mathrm{Pb}(\mathrm{II})$ adsorbed also depends on $\mathrm{pH}$ of solution. Adsorption kinetics of $\mathrm{Pb}(\mathrm{II})$ onto CFA could be approximated with pseudo second order kinetic model with the rate constant is $0.298 \mathrm{~g} \mathrm{~mol}^{-1} \mathrm{~min}^{-1}$.

\section{ACKNOWLEDMENT}

We are grateful to Directorate for Research and Community Service, Directorate General of Higher Education, Ministry of National Education Republic Indonesia for research grants with grant number DIPA023.04.2.189822/2013.

\section{REFERENCES}

[1] A.K. Kondru, P. Kumar, T.T. Teng, S.H. Chand, K.L. Wasewar, Synthesis and characterization of Na-Y zeolite from coal fly ash, its effectiveness in removal of dye from aqueous solution by wet peroxide oxidation. Arch. Environ. Sci., 5, 2011, 46-54.

[2] C.D. Woolard, K. Petrus, M.V.D. Horst, The use of a modified fly ash as an adsorbent for lead, Water SA. 26(4), 2000, $531-536$.

[3] F. Montagnaro, L. Santoro, Reuse of coal combustion ashes as dyes and heavy metal adsorbents : effect of sieving and demineralization on waste properties and adsorption capacity. Chemical Engineering Journal. 150, 2009, 174-180.

[4] J.A. Hefne, W.K. Mekhemer, N.M. Alandis, O.A. Aldayel, T. Alajyan, Kinetic and thermodynamic study of the adsorption of $\mathrm{Pb}$ (II) from aqueous solution to the natural and treated bentonite, International Journal of Physical Sciences, 3, 2008, 281-288.

[5] R. Apiratikul, P. Pavasant, Sorption of $\mathrm{Cu}^{2+}, \mathrm{Cd}^{2+}$ and $\mathrm{Pb}^{2+}$ using modified zeolite from coal fly ash, Chemical Engineering Journal, 144, 2008, 245-258.

[6] T. Klamrassame, P. Pavasant, N. Laosiripojana, Synthesis of zeolite from coal fly ash : its application as water sorbent, Engineering Journal, 14(1), 2010, 37-44.

[7] V.K. Jha, M. Matsuda, Miyake, Sorption properties of the activated carbon-zeolite composite prepared from coal fly ash for $\mathrm{Ni}^{2+}, \mathrm{Cu}^{2+}, \mathrm{Cd}^{2+}$ and $\mathrm{Pb}^{2+}$, Journal of Hazardous Materials, 160, 2008, 148-153.

[8] W. Franus, Characterization of X-type zeolite prepared from coal fly ash, Pol. J. Environ. Stud, 21(5), 2012, 337-343. 